\title{
EL PRINCIPIO DE MÍNIMA INTERVENCIÓN DEL ESTADO EN LOS ASUNTOS FAMILIARES EN LOS SISTEMAS NORMATIVOS CHILENO Y ESPAÑOL
}

[The Principle of Minimal Intervention by the State in Family Matters in the Chilean and Spanish Regulatory Systems]

\author{
Ruperto Pinochet Olave* \\ Centro de Estudios sobre Derechos de la Infancia y la Adolescencia \\ Universidad de Talca, Chile \\ IsaAC RaVetLlat Ballesté** \\ Centro de Estudios sobre Derechos de la Infancia y la Adolescencia \\ Universidad de Talca, Chile
}

\begin{abstract}
RESUMEN
El artículo expone el modelo normativo de protección a la familia y a la infancia establecido en los ordenamientos jurídicos chileno y español. Si bien es cierto que ambos ordenamientos encomiendan de manera preferente a los progenitores la obligación de prestar determinadas funciones encaminadas a dar efectividad a los derechos fundamentales
\end{abstract}

\begin{abstract}
This article puts forth the regulatory model of family and childhood protection established in the Chilean and Spanish legal systems. Although both systems primarily entrust parents with the obligation to carry out certain functions to ensure that fundamental rights are provided to minors, it is also true that the separation between public
\end{abstract}

ReCiBido el 20 de noviembre de 2014 y ACEPTADO el 30 de mayo de 2015

* Profesor de derecho civil de la Facultad de Ciencias Jurídicas y Sociales de la Universidad de Talca. Director del Centro de Estudios sobre Derechos de la Infancia y la Adolescencia de la Universidad de Talca. Dirección postal: Campus Lircay s/n, Talca, VII Región, Chile. Correo electrónico: rpinochet@bonafides.cl

** Profesor de derecho civil de la Facultad de Ciencias Jurídicas y Sociales de la Universidad de Talca. Subdirector del Centro de Estudios sobre Derechos de la Infancia y la Adolescencia de la Universidad de Talca. Vocal del Observatorio de la Infancia de la Generalitat de Catalunya. Secretario General de la Asociación para la Defensa de los Derechos de la Infancia y la Adolescencia. Dirección postal: Campus Lircay s/n, Talca, VII Región, Chile. 
de las personas menores de edad; no es menos cierto que la separación entre lo público y lo privado cada vez se encuentra más difuminada y las responsabilidades más compartidas entre la familia y los poderes públicos. Efectivamente, esa tensión permanente que viven lo privado y lo público debe traducirse en una clara delimitación de su ámbito de afectación, para evitar una excesiva intromisión del Estado en los espacios vivenciales propios de las familias.

\section{Palabras Clave}

Protección de memores - Mínima intervención estatal - Tuición pública y privada. and private issues is getting more diffuse and responsibilities are being increasingly shared between the family and public authorities. Effectively, that permanent tension between the private and public issues must be translated into a clear definition of the area of influence, to avoid excessive involvement of the State in the living spaces that are inherent to families.

\section{KEYWORDS}

Child Protection - Minimal intervention by the State - Public and private tuition.

\section{FORMULACIÓN Y CONTENIDO DEL PRINCIPIO DE MÍNIMA INTERVENCIÓN DEL ESTADO EN EL DERECHO DE FAMILIA}

El principio de que trata este artículo $^{1}$, que viene abriéndose paso en la doctrina y la legislación especialmente en el derecho comparado ${ }^{2}$, consiste en que el Estado no puede intervenir a través de sus órganos en la familia contra la voluntad de la propia unidad familiar, sino en casos graves y extremos $^{3}$. En otras palabras, que el Estado ostenta un rol meramente

\footnotetext{
${ }^{1}$ Para Cillero Bruñol, Miguel, El interés superior del niño en el marco de la Convención Internacional de los derechos del Niño, en Justicia y Derechos del Niño (UNICEF) (2007) 9, p. 133, en el marco de un sistema jurídico basado en el reconocimiento de derechos, puede afirmarse que los principios son derechos que permiten ejercer otros derechos y resolver conflictos entre derechos igualmente reconocidos. Por su parte, Ávila, Humberto, Teoría de los principios (traducción de Laura Criado, Madrid, Marcial Pons, 2011), p. 70, sostiene que los principios son normas inmediatamente finalistas, primariamente prospectivas y con pretensión de complementariedad y parcialidad, para cuya aplicación se requiere una valoración de la correlación entre el estado de cosas que debe ser promovido y los efectos derivados de la conducta considerada para su promoción.

${ }^{2}$ Este principio se encuentra implícito en el texto de la Convención sobre los derechos del niño, al señalarse expresamente en su "Preámbulo" que "convencidos de que la familia, como grupo fundamental de la sociedad y medio natural para el crecimiento y el bienestar de todos sus miembros, y en particular de los niños, debe recibir la protección $y$ asistencia necesarias para poder asumir plenamente sus responsabilidades dentro de la comunidad'.

${ }^{3}$ Véase en este sentido: Barcia Lehmann, Rodrigo, Fundamentos del derecho de
} 
subsidiario, debiendo desarrollar las políticas de fomento y protección necesarias, e interviniendo únicamente de forma directa en la relación familiar en última instancia ${ }^{4}$.

Este principio es de aplicación tanto en el derecho de familia, como en el denominado derecho de la infancia y la adolescencia -considerado este último como una rama autónoma del ordenamiento jurídico5 - . Efectivamente, los poderes públicos única y exclusivamente debieran intervenir en

familia y de la infancia (Santiago, Thomson Reuters, 2011), pp. 26-27. También se hace eco de este principio LePIN Molina, Cristian, Los nuevos principios del derecho de familia, en Revista Chilena de Derecho Privado, 23 (2014), p. 9, quien apunta que se plantea como nuevos principios del derecho de familia: la protección de la familia, la protección del matrimonio, la igualdad entre los integrantes del grupo familiar, la protección del más débil en las relaciones de familia - interés superior del niño y cónyuge más débil, la autonomía de la voluntad y, por último, el principio de intervención mínima del Estado. Este último autor, unos años antes, ya había tratado el principio de protección del cónyuge más débil en LePIN Molina, Cristian, La autonomía de la voluntad y protección del cónyuge más débil en la determinación y formas de pago de la compensación económica, en Ius et Praxis (2012) 1, pp. 3-36.

${ }^{4}$ Véase Díaz de VALdÉs, José Manuel, Un marco constitucional para los tratamientos médicos de niños, niñas y adolescentes, en Revista Chilena de Derecho (2010) 2, p. 284. También Del Picó Rubio, Jorge, Evolución y actualidad de la concepción de familia. Una apreciación de la incidencia positiva de las tendencias dominantes a partir de la reforma del derecho matrimonial chileno, en Ius et Praxis (2011) 1, p. 53, apunta que la revalorización, en el seno del derecho de familia, de la autonomía individual se ha visto tensionada por la contradicción expuesta por el requerimiento de la intención social representada por el Estado en las situaciones críticas de la relación conyugal y de la vida familiar.

${ }^{5}$ Sin ir más lejos, la Corte Interamericana de Derechos Humanos en su Opinión Consultiva $\mathrm{N}^{\circ} 17$, de 2002 , ha fijado el sentido de la protección de los niños, niñas y adolescentes en los instrumentos internacionales a través de su objetivo último, cual es el desarrollo armonioso de la personalidad de aquellos y el disfrute de los derechos que les han sido reconocidos. Corresponde al Estado precisar las medidas que adoptará para alentar ese desarrollo en su propio ámbito de competencia y apoyar a la familia en la función que ésta naturalmente tiene a su cargo para brindar protección a los niños que la integran. Véase: Corte Interamericana de Derechos Humanos, Opinión Consultiva OC-17/2002, de 28 de agosto, solicitada por la Comisión Interamericana de Derechos Humanos, p. 61. En idéntico sentido se pronuncia Cillero BRUÑol, Miguel, El interés superior del niño en el marco de la Convención internacional de los derechos del niño, en Justicia y Derechos del Niño (UNICEF) (1999) 1, p. 51; y Cillero Bruñol, Miguel, El interés superior del niño en el marco de la Convención internacional de los derechos del niño, en Justicia y Derechos del Niño (UNICEF) (2007) 9, p. 131, quien haciendo referencia al marco internacional, apunta con acierto que la Convención sobre los derechos del niño es profundamente respetuosa de la relación niño-familia, limitando la intervención del Estado a una última instancia que supone que han fallado los esfuerzos de la familia y los programas sociales generales. 
aquellos casos en que las partes en litigio -se sobreentiende integrantes de un grupo familiar- no logran resolver sus controversias de forma pacífica o por mutuo acuerdo, o en los supuestos en que se ponga en serio riesgo o peligro la integridad física o moral de alguno de sus miembros ${ }^{6}$ : en particular si se trata de situaciones de violencia intrafamiliar, entendida esta en un sentido amplio, o de vulneración de los derechos de los niños, niñas o adolescentes ${ }^{7}$.

Para Rodrigo Barcia, el convenio regulador de la separación y del divorcio $^{8}$, el reconocimiento de un ámbito de privacidad y autonomía del niño, niña o adolescente cada vez más extenso en atención a su edad y

${ }^{6}$ Tapia Rodríguez, Mauricio, Del derecho de familia hacia un derecho de las familias en GuZmán Brito, Alejandro (editor), Estudios de derecho Civil. Jornadas Nacionales de derecho Civil. Valparaíso (Santiago, Abeledo-Perrot, 2007), III, p. 161, afirma que el derecho chileno asume, cada vez más, una noción de familia cercana a aquella identificada por el decano Carbonnier como característica de las sociedades modernas, donde ésta aparece antes como un instrumento entregado a cada uno para el desarrollo de su personalidad, dejando el derecho civil de trazar normativamente un modelo de vida, y pasando a preocuparse simplemente de remediar los conflictos (personales y patrimoniales) que surgen cuando se frustran estos proyectos familiares. Para Del Picó, Jorge, cit. (n. 4), p. 39, como sea que se valore el cambio suscitado en la apreciación pública de la familia, tras el diseño de las políticas públicas aplicadas en las últimas dos décadas y que jurídicamente se manifiesta en el derecho de familia, se debe reconocer una evolución desde una concepción predominantemente social y marcadamente institucional sobre la familia, hacia una mirada preponderantemente enfocada en el sujeto individual que la constituye y sus circunstancias afectivas.

${ }^{7}$ Lepin Molina, Cristian, cit. (n. 3), p. 47. En idéntica tendencia parece enmarcarse, como no podría ser de otra forma, la Ley $\mathrm{N}^{\circ} 19.968$, que Crea los tribunales de familia, en Diario Oficial de 30 de agosto de 2004, que en su artículo 13 estipula que la intervención judicial de oficio deberá observarse respecto de medidas destinadas a otorgar protección a los niños, niñas y adolescentes y a las víctimas de violencia intrafamiliar. Por su parte, ZúNIIGA, Yanira - Turner, Susan, Sistematización comparativa de la regulación de la familia en las Constituciones latinoamericanas, en Revista de Derecho de la Universidad Católica del Norte (2013) 2, p. 284, tras un estudio pormenorizado de las principales Constituciones vigentes en la región americana, concluyen que en relación al rol asignado por los textos constitucionales al Estado respecto de la familia, la gran mayoría de ellos le atribuyen un rol garante o protector. Solo Argentina y México, apuntan las referidas autoras, le confieren tal función a la ley.

${ }^{8}$ Ilustrativas son, este sentido las palabras pronunciadas por RodRíGuEz PINTO, María Sara, El cuidado personal de niños y adolescentes en la familia separada: criterios de resolución de conflictos de intereses entre padres e hijos en el nuevo derecho chileno de familia, en Revista Chilena de Derecho (2009) 3, p. 547, al apuntar que la convención entre el padre y la madre debe configurarse como un vehículo que introduce un mayor margen de actividad a la autonomía de la voluntad... y evita la prematura intervención judicial en el conflicto. 
estado de madurez ${ }^{9}$, o el aumento de la autonomía privada en torno a los regímenes patrimoniales del matrimonio son, entre otros ${ }^{10}$, claros ejemplos de lo apuntado ${ }^{11}$. De este modo se garantiza a los individuos, incluso en este sector del ordenamiento jurídico, una esfera privada de derechos individuales que no puede ser violentada, ni siquiera por la autoridad pública. Sirva a título meramente ilustrativo el respeto a la libertad individual o la salvaguarda de la intimidad personal y familiar ${ }^{12}$. Se da pues, cada vez un mayor influjo de los derechos fundamentales en el ámbito del derecho privado $^{13}$.

${ }^{9}$ Tal y como señala Mason, Mary Ann, ¿Una voz para el niño?, en Revista de Derechos del Niño (UDP-UNICEF) (2004) 2, p. 122, en la medida que el niño va madurando, la asistencia de los padres en el ejercicio de sus derechos es cada vez menos necesaria, hasta llegar al punto que se hace del todo redundante.

${ }^{10}$ Díez-Picazo y Ponce de León, Luis, La reforma del Código Civil en materia de patria potestad, en La reforma del derecho de familia, matrimonio, separación, divorcio, régimen económico matrimonial, filiación y patria potestad. Jornadas hispalenses sobre la reforma del derecho de familia (Sevilla, Imprenta Sevilla, 1983), p. 298; El MISMO, Notas sobre la reforma del Código Civil en materia de patria potestad, en Anuario de Derecho Civil, 35 (enero- marzo de 1982), p. 10.

${ }^{11}$ Barcia Lehmann, R., cit. (n. 3), pp. 26-27.

${ }^{12}$ Ortuño Muñoz, Pascual, Los procesos en los juzgados de familia (Consejo General del Poder Judicial), pp. 113-119.

${ }^{13}$ Arancibia Obrador, María José - Cornejo Aguilera, Pablo, El derecho de familia en Chile. Evolución y nuevos desafios, en Ius et Praxis (2014) 1, p. 317. En este mismo sentido se ha venido interpretando el artículo 8 del Convenio europeo para la protección de los derechos humanos y de las libertades fundamentales, en vigor desde el 3 de septiembre de 1953 y sucesivamente revisado y completado por diversos protocolos adicionales. Este precepto reconoce en su apartado primero, el derecho de toda persona al respeto de su vida privada y familiar, y a continuación, en su apartado segundo, establece que no podrá haber injerencia de la autoridad pública en el ejercicio de este derecho sino en tanto en cuanto esta intromisión esté prevista por la ley y constituya una medida que, en una sociedad democrática, sea necesaria para la seguridad nacional, la seguridad pública, el bienestar económico del país, la defensa del orden y la prevención de las infracciones penales, la protección de la salud o de la moral, o la protección de los derechos y las libertades de los demás - los criterios para proceder a la interpretación del parágrafo segundo del artículo $8 \mathrm{CEDH}$., los encontramos detallados en la sentencia del Tribunal Europeo de Derechos Humanos de 6 de septiembre de 1978, asunto "Klas and others v. Germany". Además, ha sido el propio Tribunal Europeo de Derechos Humanos, que en su "case law" ha procedido a interpretar de manera dinámica y extensa el contenido del artículo 8 $\mathrm{CEDH}$. Así, mientras que en su concepción inicial se entendía que el Convenio de Roma no establecía más que obligaciones negativas, prohibiciones de injerencia en la "vida privada y familiar" (sentencia del Tribunal Europeo de Derechos Humanos de 23 de julio de 1968, asunto relativo a ciertos aspectos del régimen lingüístico de la educación en Bélgica), pronto la jurisprudencia del Tribunal de Estrasburgo admitió 


\section{RELACIÓN ESTADO-PARTICULARES EN EL DERECHO DE FAMILIA}

Partiendo de lo apuntado en el apartado precedente, se concibe la actuación del Estado como un mecanismo de garantía de los derechos fundamentales de los ciudadanos, y es por ello que los poderes públicos no pueden estar indiferentes ante ciertos problemas, deben por el contrario, proveer soluciones y no dejar que sean los propios particulares los que de manera exclusiva deban solventarlos. Éstos y el Estado deben colaborar ${ }^{14}$, por tanto, de manera estrecha en alcanzar el grado de bienestar que corresponde ${ }^{15}$. Así, el derecho de familia ya no puede ser considerado como un

que la redacción de este artículo también contenía obligaciones positivas a cargo de los Estados. En este sentido se ha pronunciado el Tribunal Europeo en sentencia de 13 de junio de 1979, en el asunto "Marckx v. Belgium": "este artículo -en referencia al artículo 8 CEDH.- tiene como objetivo fundamental la salvaguarda de los individuos frente a las injerencias arbitrarias de los poderes públicos. Pero a esta obligación negativa del Estado se le tienen que añadir obligaciones de carácter positivo inherentes al respeto efectivo de la vida familiar. El Estado debe actuar de manera que permita a los interesados desarrollar una vida familiar normal'. A esta sentencia le han seguido, entre otras, con el mismo planteamiento: la sentencia de 26 de marzo de 1985, en el asunto "X and Y v. The Netherlands"; la sentencia de 18 de diciembre de 1986, en el asunto "Johnston and others v. Ireland"; y la sentencia de 7 de julio de 1989, en el asunto "Gaskin v. United Kingdom". Aspecto este último, que debiera potenciar la autonomía de la voluntad de los particulares en las relaciones familiares frente a un exacerbado intervencionismo estatal más propio de otros tiempos.

${ }^{14}$ Flaquer Vilardebò, Lluís (coordinador), Informe sobre la situación de la familia en Cataluña. Un intento de diagnóstico (Barcelona, Departamento de Bienestar Social de la Generalitat de Catalunya, 2002), p. 184, afirma que el recinto doméstico ya no es un coto cerrado y recibe el impacto de numerosos factores exteriores, desde la política social hasta las leyes protectoras de la infancia y la adolescencia. Ya no puede seguir afirmándose que la tendencia imperante en la familia de nuestras sociedades es la privatización; tanto se da ésta, como en palabras del propio autor, la "publicización". En este mismo sentido se pronuncia Glendon, Mary Ann, The Transformation of Family Law. State, Law, and Family in the United States and Western Europe (Chicago, The University of Chicago Press, 1989), pp. 291-313, quien considera que en nuestra sociedad -se refiere a la sociedad occidental- la familia ha dejado de ser la cédula básica; ahora lo son los individuos. También, BRULleT, Cristina - RocA, Clara, Relaciones familiares y autoridad, en Infancia, familias y cambio social en Cataluña (Barcelona, Instituto de Infancia y Mundo Urbano. Observatorio de la Infancia y las Familias, 2005), I, p. 72, plantean que la cuestión de cómo se debe concretar el equilibrio entre el derecho a la privacidad de personas y familias, $y$ la necesidad de una acción pública que asegure el desarrollo físico, psicológico, moral y social de toda la ciudadanía es un debate abierto y constante en toda democracia.

${ }^{15}$ Borras Rodríguez, Alegría, El interés del menor como factor de progreso y unificación del derecho internacional privado (discurso de ingreso en la Academia de Jurisprudencia y Legislación de Cataluña), en Revista Jurídica de Cataluña (1994) 4, 
sistema que afecta exclusivamente a intereses particulares, sino que, por el contrario, ha ido adquiriendo de manera paulatina un fuerte contenido público, con aspectos que se refieren tanto a la imperatividad de las normas que regulan los procesos relacionados con cuestiones de derecho de familia como a la asistencia social de todo tipo que debe prestar la Administración Pública a la institución familiar ${ }^{16}$.

p. 965, considera que la superación de la distinción entre lo público y lo privado es patente en esta materia -refiriéndose a los derechos de la infancia y la adolescencia-. Para esta autora es importante el hecho de que la cuestión ahora no se encuentra en el estricto ámbito de lo tradicionalmente denominado "privado", sino que hay una fuerte incidencia de la actividad pública, lo cual ha forzado también la evolución de la materia. Así, una cuestión perteneciente tradicionalmente al ámbito de la familia, cual es la protección de las personas menores de edad, dispone ahora de una amplia proyección de carácter público, en atención, precisamente, al interés superior del niño, que excede del círculo estrictamente familiar. A esta misma conclusión llega Fernández Masía, Enrique, Las entidades públicas y la protección de los menores extranjeros en España, en Actualidad Civil, 19 (mayo, 1998), pp. 427-428, al considerar que las formas de protección de las personas menores de edad han sufrido una profunda transformación en las últimas décadas reflejándose, básicamente, en la creciente acentuación de la dimensión pública frente a la puramente privada en la mayoría de los ordenamientos jurídicos. También en este sentido se pronuncia Vlaardingerbroeck, P., Child Care and Protection Measures and Minor Foreigners: The Legal Position of Minors, en Lowe, N. - Douglas, G. (editores), Family Across Frontiers (London, 1996), pp. 499-513. Por su parte, LAZARO GONZÁlEZ, Los menores en el derecho español (Madrid, Tecnos, 2002), p. 148, llega a la conclusión de que la intervención administrativa en la familia $-y$ la legislación que regula dicha actuación- se ampara en la superación de la identificación entre familia y derecho civil de familia como realidades en las que no era posible actuación pública alguna. Finalmente, Garcés Sanagustín, Ángel, Acción social. La protección de menores, en Embid Irujo, Antonio (director), Derecho público aragonés (Zaragoza, El Justicia de Aragón, 2005), p. 541, corrobora la idea de que en ocasiones es muy difícil deslindar lo que son aspectos exclusivamente propios del derecho privado de ciertas actuaciones administrativas en este ámbito.

${ }^{16}$ Grosman, Cecilia - Martínez Alcorta, Irene, Familias ensambladas. Nuevas uniones después del divorcio. Ley y creencias. Problemas y soluciones legales (Buenos Aires, Editorial Universidad, 2000), p. 29, manifiestan que la creciente privatización de la familia ha llevado concomitantemente a una reducción del orden público. Los particulares, entienden estas autoras, en mayor medida, deciden la organización de su vida íntima, sin que la ley y la justicia pueda interferir en dicha esfera. Sin embargo, si lo privado es excluido del dominio público, al mismo tiempo la sociedad y el Estado controlan a la familia en la medida en que los comportamientos y acciones de los adultos afecten o constituyan un riesgo para los niños. Concluyen su análisis afirmando que, por una parte se produce una suerte de desinstitucionalización de la familia al darse un mayor juego a la voluntad individual, mientras que por la otra parte aparece una intervención pública que regula los efectos sociales de esta libertad de la esfera privada. 
Esa naturaleza de orden público, de ius $\operatorname{cogens}^{17}$, justifica una interpretación específica, finalista, de algunas normas concretas a favor de las personas menores de edad ${ }^{18}$. La idea de que las relaciones intrafamiliares son asunto privado es una ilusión, por el contrario, su funcionamiento está pautado, controlado. La familia se ve obligada a dar una imagen honorable de sí misma; es vulnerable a las presiones del entorno, en otras palabras, es accesible a las intervenciones directas de las autoridades: por citar un ejemplo, las trabajadoras sociales penetran en el interior de los hogares, actúan sobre los guardadores, elaboran informes y para el caso de que se produzca un desajuste toman medidas ${ }^{19}$.

En definitiva, en el actual sistema, la separación entre lo público y lo privado se difumina y las responsabilidades se comparten, cada vez en mayor medida, entre la familia y los poderes públicos. En este sentido, la Convención sobre los derechos del niño, texto ratificado por el Estado chileno el 14 de agosto de 1990, atribuye tanto a los progenitores como a los poderes públicos la responsabilidad de brindar asistencia y protección a los niños, niñas y adolescentes ${ }^{20}$. Por un lado, los poderes públicos tienen

${ }^{17}$ Véase Roca I Trías, Encarna, Familia, familias y derecho de la familia, en Anuario de derecho Civil, 4 (1990), p. 1056. Por su parte, también tener presentes los importantes pronunciamientos emitidos por parte de la jurisprudencia española. Así, la sentencia del Tribunal Constitucional 120/1984, de 10 de diciembre (FJ 2), que dispone que "no es ocioso traer a colación alguna somera reflexión en orden al carácter de todo el proceso matrimonial, en el que se dan elemento no dispositivos, sino de ius cogens, precisamente por derivar y ser un instrumento al servicio del derecho de familia" y 4/2001, de 15 de enero (FJ 4). En ese mismo sentido se pronuncian la sentencia del Tribunal Supremo (Sala de lo Civil), de 2 de diciembre de 1987 (FJ 2) al entender que "en el proceso matrimonial conviven con el elemento dispositivo otros de ius cogens derivados de la especial naturaleza del derecho de familia; de 15 de marzo de 1989 (FJ 1) que viene a declarar que "el sentido iusprivatista del derecho de familia ha evolucionado en los últimos años hasta el punto de romper los estrechos moldes en que se encontraba enmarcado para pasar a integrarse en el ius cogens y en el ámbito del derecho público. Esta nueva naturaleza ha marcado las instituciones que la componen y transido los procesos de principios que han sustituido a los arcaicos y tradicionales"; lo mismo que la de 5 de mayo de 1989 (FJ 1) que reproduce el contenido de la anterior.

${ }^{18}$ Rivero Hernández, Francisco, Protección civil de los menores en España. Líneas fundamentales en Oliverra, Guiherme (editor), Direito da infancia, da juventude e do envelhecimento (Centro de Direito da Família, Faculdade de Direito da Universidade de Coimbra, N 9, Coimbra, Coimbra Editora, 2005), pp. 15-17.

${ }^{19}$ Rochefort, Christiane, Los niños primero (Barcelona, Anagrama, 1982), p. 26, define de manera muy gráfica esta idea, al apuntar que esta ilusión de un territorio privado -refiriéndose a la familia- es una trampa en la que prácticamente todo el mundo cae.

${ }^{20}$ Véanse, en este sentido, los artículos 5 y 18,1 y 2 de la Convención sobre los derechos del niño. En igual línea se pronuncia el artículo 19 del Convenio americano 
la responsabilidad de diseñar e implementar políticas públicas y planes nacionales de infancia y adolescencia dirigidos a garantizar la plena efectividad de sus derechos, tanto en los aspectos personales como sociales, en el ámbito de la familia, la salud, la educación, la justicia, la cultura, el consumo o el ocio ${ }^{21}$. Por otra parte, nuestro ordenamiento jurídico encomienda de manera preferente a los padres la obligación de prestar, en el seno de la familia, determinadas funciones encaminadas a dar efectividad a los derechos fundamentales de las personas menores de edad ${ }^{22}$.

de derechos humanos, en el cual se estatuye que "todo niño tiene derecho a las medidas de protección requeridas por su condición de menor, de parte de su familia, la sociedady el Estado". Añádanse a ello las palabras pronunciadas por Acuña SAN MARTín, Marcela, Efectos jurídicos del divorcio (Santiago de Chile, Abeledo Perrot, 2011), p. 93, quien sostiene que a tenor de la Convención sobre los derechos del Niño la persona menor de edad es un sujeto de derechos, un titular autónomo de derechos distinto de sus progenitores, aun cuando su autonomía se encuentre en progreso y no esté plenamente desarrollada: el núcleo del principio y norma jurídica del interés del niño está, por ende, en considerar que el niño, niña o adolescente es ante todo persona.

${ }^{21}$ Véase: Palma del Teso, Ángeles de, La protección de los menores por las administraciones públicas, en Revista Jurídica de Cataluña (2004) 2, pp. 38-39. También, Gala Vallejo, César, La familia y su protección en España (Madrid, Ministerio de Trabajo y Asuntos Sociales, 2002), pp. 99-105. En opinión de BRULlet, Cristina - Torrabadella, Laura, La infancia en las dinámicas de transformación familiar, en Gómez-Granell, Carme - García Milá, Mercè - Ripol-Millet, Aleix - Panchón, Carme (coordinadores), Infancia y familias: realidades y tendencias (Barcelona, Ariel, 2004), p. 37, los niños y niñas son agentes activos en sus relaciones familiares y también son sujetos con derechos propios en nuestra sociedad democrática. En este sentido, el Estado, independientemente de la familia, tiene responsabilidades propias con ellos en tanto que son ciudadanos de derecho y debe asegurarles una vida digna. En aras de este objetivo, los gobiernos desarrollan políticas educativas, sanitarias y familiares, pero también políticas específicas de apoyo a aquellos que viven en situaciones de mayor vulnerabilidad social.

${ }^{22}$ El Pacto internacional de derechos civiles y politicos, de 19 de diciembre de 1966 -ratificado por Chile el 10 de febrero de 1972- dispone en su artículo 24,1 que "todo niño tiene derecho, sin discriminación alguna por motivos de raza, color, sexo, idioma, religión, origen nacional o social, posición económica o nacimiento a las medidas de protección que su condición de menor requiere, tanto por parte de su familia como de la sociedad y del Estado". En la legislación interna chilena se incorporó entre las obligaciones y derechos de los padres, el deber de la preocupación fundamental por el interés superior del niño, incluyendo el brindarles bienestar y el guiarlos en el ejercicio de sus derechos esenciales -artículo 222 CC.-. Sin embargo, ni la normativa doméstica chilena ni los tratados internacionales en materia de derechos humanos, abordan de manera suficiente un problema crítico, cual es el de los niños, niñas y adolescentes no amparados por la protección de sus progenitores, tutores o guardadores en general; circunstancia ésta en la que el Estado debe prever de manera más clara y concisa medidas que atiendan a los niños envueltos en tales situaciones, en 
Así, a pesar de tratarse de un ámbito en el que coexisten dos ordenamientos distintos - que, además, responden a principios en muchas ocasiones antagónicos -, debe recalcarse el carácter subsidiario de la actuación pública respecto de lo que son las responsabilidades que, en primer término, corresponden a quienes tienen a las personas menores de edad a su cargo. Ahora bien, las administraciones públicas no son del todo ajenas a esta tarea privada, sino que se les reserva el deber de colaborar con la familia con el fin de favorecer y hacer posible en todo caso que los progenitores, tutores o guardadores cumplan con sus obligaciones para con los niños, las niñas y los adolescentes ${ }^{23}$.

Por ende, la familia es la institución primera y directamente responsable de la guarda de los niños, niñas y adolescentes, de su crianza y formación ${ }^{24}$. Tanto los progenitores como los hijos tienen reconocido con el más alto rango el derecho a la vida familiar. En virtud de ello, las personas meno-

las condiciones más parecidas a las de un hogar. Por su parte DíAZ DE VALDÉs, José Manuel, Un marco constitucional para los tratamientos médicos de niños, niñas y adolescentes, en Revista Chilena de Derecho (2010) 2, p. 284, apunta con claridad que es la institución familiar la que da respuesta y cumplimiento al derecho de asistencia de los niños, siendo la primera y preferentemente llamada a tal rol.

${ }^{23}$ En opinión de O'Donell, Daniel, La Convención sobre los derechos del niño: estructura y contenido (materiales de un curso dirigido a especialistas del área jurídica de la niñez organizado por el Instituto Interamericano de la Niñez, 2005), p. 10, el artículo 5 de la Convención sobre los derechos del niño, relativo al papel de los padres en el ejercicio de los derechos del niño, recoge un principio general que constituye la piedra angular de la Convención. Las responsabilidades, los derechos y los deberes de los padres hacia el niño, de acuerdo con el anterior principio, son dobles: por una parte, ha de permitirle ejercer los derechos reconocidos en la Convención, y por otro ha de proporcionarle "la dirección y orientación apropiadas" para su ejercicio. Ambas funciones, la permisiva y la orientadora, han de ser consonantes con la "evolución de las facultades del niño". Asimismo, la Carta Europea de los Derechos del Niño, aprobada por Resolución A3-0172/92, de 8 de julio de 1992, establece en su artículo 8 apartado once que "corresponde a los padres en prioridad el dar al niño una vida digna y, en la medida de sus recursos financieros, los medios para satisfacer sus necesidades". Seguidamente se dispone que "los Estados deberán asegurar a los padres la oportuna asistencia en las responsabilidades que les competen, a través de los correspondientes organismos, servicios y facilidades sociales". Véase también en este sentido los artículos 17,1 y 19 de la Convención americana sobre derechos humanos, suscrita en San José de Costa Rica, el 22 de noviembre de 1969.

${ }^{24}$ En ese sentido, se pronuncian los artículos 5, 9,1 y 3 y 18 de la Convención sobre los derechos del niño y el apartado $3^{\circ}$ de la Declaración sobre los principios sociales y jurídicos relativos a la protección y el bienestar de los niños, adoptada por la Asamblea General de las Naciones Unidas, el 3 de diciembre de 1986. 
res de edad deberán crecer siempre que sea posible al amparo y bajo la responsabilidad de sus padres ${ }^{25}$.

Además de colaborar con la familia en el ejercicio de sus funciones de asistencia y protección de las personas menores de edad, las administraciones públicas quedan obligadas a velar para que ese encargo se haga efectivo. De tal manera que, sólo en tanto éstos -padres, tutores, o guardadoresfalten al cumplimiento de sus deberes respecto del niño, niña o adolescente se aplicarán las medidas de protección pública previstas legalmente.

En otras palabras, entendemos que la actuación protectora de los poderes públicos -sea por vía administrativa o judicial- se guía por el principio de subsidiariedad progresiva, esto es, el alcance e intensidad de la intervención del Estado vendrá condicionado por el grado de desatención o desprotección que sufra la persona menor de edad en el seno de su familia ${ }^{26}$. Lo mismo cabría afirmar al tratar del conflicto de intereses en el

${ }^{25}$ Para Orrego Acuña, Juan Andrés, Temas de derecho de familia (Santiago de Chile, Metropolitana, 2007), p. 219, tanto la denominada "autoridad parental", referida a la persona del menor, como la "patria potestad", referente a los bienes del menor, han de ser ejercitadas en función del interés de los menores, y no del interés de los progenitores. Por su parte, DÍAZ DE VALDÉs, José Manuel, Un marco constitucional para los tratamientos médicos de niños, niñas y adolescentes, en Revista Chilena de Derecho (2010) 2, p. 295, tras vincular el principio del interés superior del niño con la noción del bien común, afirma que tal relación ha sido recogida expresamente por el legislador chileno en el artículo 222 inciso $2^{\circ}$ del Código Civil, el cual obliga a los padres a procurar la "mayor realización espiritual y material posible" del niño como forma de servir a su interés superior. Finalmente, Rodríguez PinTo, María Sara, El cuidado personal de niños y adolescentes en la familia separada: criterios de resolución de conflictos de intereses entre padres e hijos en el nuevo derecho chileno de familia, en Revista Chilena de Derecho (2009) 3, p. 564, sostiene que en aquellos casos en que tanto los intereses de los padres como de los hijos sean igualmente legítimos, cabe ponerlos en jerarquía. En este supuesto, mantiene la autora, parece conveniente preferir el interés del niño, siendo a los progenitores a quienes corresponde sacrificar sus intereses personales en función del interés de sus hijos y no estos sacrificar el desarrollo armónico de su personalidad en función del interés de sus padres.

${ }^{26}$ Una cuestión delicada que no podemos pasar por alto es la armonización del juego de intereses en la relación a tres bandas. Estado - progenitores (o personas encargadas del cuidado de los niños e hijos). No obstante, en este triángulo hay situaciones en que aparece clara la responsabilidad de los poderes públicos, la que incluso pasa a ser directa y no meramente subsidiaria de la de los padres o guardadores. Este último sería el caso de las personas menores de edad en conflicto con la ley penal que han sido privadas de libertad, en que parece evidente que es el Estado el que debe velar incluso por el desarrollo integral del adolescente. Ello puede extraerse del caso "Instituto de Reeducación del Menor vs. Paraguay", en el que la Corte Interamericana de Derechos Humanos, en Sentencia de 2 de septiembre de 2014, concluye que "en materia del derecho a la vida, cuando el Estado se encuentra en presencia de niños 
ejercicio de la autoridad parental y la patria potestad de los hijos y las hijas. Efectivamente, en aquellos casos en que el ejercicio, por los titulares de la potestad, de las funciones que tengan legalmente encomendadas, pueda menoscabar los derechos del hijo menor a cargo, la intromisión del Estado en las relaciones paterno-filiales, no sólo será lícita, sino que, además, vendrá exigida por la tutela del interés superior del niño, verdadera piedra angular de toda la legislación relativa al mismo ${ }^{27}$.

privados de libertad, como ocurre mayormente en el presente caso, tiene, además de las obligaciones señaladas para toda persona, una obligación adicional establecida en el artículo 19 de la Convención Americana. Por una parte, debe asumir su posición especial de garante con mayor cuidado y responsabilidad, y debe tomar medidas especiales orientadas en el principio del interés superior del niño. Por otra, la protección de la vida del niño requiere que el Estado se preocupe particularmente de las circunstancias de la vida que llevará mientras se mantenga privado de libertad, puesto que ese derecho no se ha extinguido ni restringido por su situación de detención o prisión. En este sentido, los artículos 6 y 27 de la Convención sobre los derechos del Niño incluyen en el derecho a la vida la obligación del Estado de garantizar en la máxima medida posible la supervivencia y el desarrollo del niño" [disponible en: http://www.corteidh.or.cr/docs/casos/articulos/ seriec_112_esp.pdf, consultado el 05 de marzo de 2015].

${ }^{27}$ En opinión de GÓmez de LA TORRE VARGAS, Maricruz, El interés superior del niño, en Gaceta Jurídica, 328 (2000), p. 23, puede otorgarse una triple función al principio del interés superior del niño: es una garantía para el menor, debido a que toda decisión que le concierna debe considerar, fundamentalmente, sus derechos; asimismo, es una norma orientadora que no sólo obliga a los legisladores y jueces sino a todas las instituciones públicas y privadas; $y$, por último, también debe ser vista como una norma de interpretación y de resolución de conflictos. Por su parte, Gatica, Nora - Chaimovic, Claudia, La justicia no entra en la escuela. Análisis de los principales principios contenidos en la Convención sobre los derechos del Niño, en La Semana Jurídica (del 13 al 19 de mayo de 2002), pp. 14-16, afirman que el llamado interés superior del niño debe ser entendido como un término relacional o comunicacional, y significa que en casos de conflicto de derechos de igual rango, el derecho de prioridad del interés superior del niño prima sobre cualquier otro que pueda afectar derechos fundamentales del niño. Así, concluyen estas autoras, ni el interés de los progenitores, ni el de la sociedad, ni el del Estado pueden ser considerados prioritarios en relación a los derechos del niño. Por último, Rodríguez Pinto, María Sara, El cuidado personal de niños y adolescentes en la familia separada: criterios de resolución de conflictos de intereses entre padres e hijos en el nuevo derecho chileno de familia, en Revista Chilena de Derecho (2009) 3, p. 566, refiriéndose de forma específica al ámbito del cuidado personal de los hijos y al derecho de los progenitores a mantener con ellos una relación directa y regular, apunta que el interés superior del niño en este contexto se convierte también en un criterio, baremo o standard de adjudicación de litigios (artículo 242 inciso $2^{\circ}$ del Código civil y artículo 16 de la Ley creadora de los Tribunales de Familia). 
Tal como señaláramos en el apartado inicial del presente estudio, nos ha llamado poderosamente la atención el hecho de que en nuestro país no se encuentre recogido de forma expresa tal principio ni dentro de aquellos que inspiran el derecho de familia, en general, como tampoco en aquellos que resultan aplicables, más precisamente, al derecho matrimonial y de la niñez ${ }^{28}$.

Con todo, si bien no hemos encontrado referencias legales explícitas al mencionado principio, en nuestro medio sí se ha entrado en la discusión sobre los límites de la autonomía familiar y el derecho o no del Estado para intervenir en tan reducido ámbito ${ }^{29}$. En tal sentido, y adoptando una de las posturas antagónicas que hemos delineado, Corral, en un interesante tra-

${ }^{28}$ No hemos podido encontrar en el derecho de familia chileno la sistematización de los principios del derecho de familia. Más bien se trata en los textos de las características del derecho de familia, las que, para los efectos de nuestro análisis no son pertinentes. Principios encontramos en las sub ramas en que podemos estimar se divide el derecho de familia, a saber: derecho matrimonial, derecho de la niñez y de la adolescencia y, Filiación. Para el derecho matrimonial Del Picó Rubio, Jorge, Derecho matrimonial chileno (Santiago, Abeledo Perrot, 2010), pp. 115 ss., reconoce los siguientes principios agrupados en dos bloques: principios explícitos y principios implícitos. Dentro del primero, reconoce la protección de la institución familiar, la valoración del matrimonio como vínculo social privilegiado e intervención judicial a favor de su preservación, valoración de la libertad nupcial, protección de los grupos de mayor vulnerabilidad, el interés superior de los hijos y del cónyuge más débil. Dentro de los principios implícitos, cree ver la valoración de la responsabilidad comunitaria y social en la protección de la familia, la valoración de la estabilidad familiar, la valoración de la igualdad jurídica de los cónyuges y la valoración de la autonomía moral expresada en la adopción de un sistema matrimonial con pluralidad de fe de celebración. Si bien es interesante y valioso el esfuerzo de sistematización de los principios para el ámbito del derecho matrimonial, no hace más que reafirmar nuestra tesis, pues no alude al principio de no o mínima intervención, que podría resultar perfectamente aplicable en tal área del derecho de familia.

${ }^{29}$ Reveladoras son las palabras que ya hace unos años pronunció Domínguez Hidalgo, Carmen, Los principios que informan el derecho de familia chileno: su formulación clásica y su revisión moderna, en Revista Chilena de Derecho (2005) 2, p. 210, quien, en primer lugar, sostenía que las profundas transformaciones operadas en el derecho de familia han estado animadas en general por el afán de asegurar libertad, igualdad y equidad. Esas son, según la autora, las tres grandes líneas rectoras que emergían por doquier; en p. 214, finalizaba afirmando que el prisma desde el cual se mira a la familia ha variado, centrándose en el presente más en los individuos que la componen que en la entidad familiar misma. Así, concluía, aunque se sigue percibiendo la familia como un conjunto de individuos unidos por ciertos vínculos, 
bajo, sostiene una especie de autonomía moral de la familia en la adopción de sus decisiones importantes ${ }^{30}$, afirmando que "debiera también hacerse un esfuerzo por evitar la judicialización de las discrepancias familiares, que constituyen una lesión a la privacidad familiar. Instancias de mediación o composición de los conflictos matrimoniales y familiares, que propendan a que las decisiones familiares sean adoptadas de un modo concertado, parecen garantizar mejor el derecho a la privacidad de la familia"31.

Debemos advertir que el citado autor reserva el respeto de la intimidad familiar, sea como dimensión del derecho individual a la privacidad o como derecho de titularidad grupal, principal y esencialmente a la familia constituida vía matrimonial ${ }^{32}$.

La mencionada autonomía moral de la familia en la toma de sus decisiones importantes nos lleva en algún sentido al principio de no intervención. Este derecho a la intimidad familiar podría, entonces, enfocarse desde una doble perspectiva: la sustantiva, como delimitación del derecho subjetivo de los individuos; y la adjetiva, en cuanto límite a la actividad jurisdiccional. Pues bien, sería precisamente en esta última área en la que podría encuadrarse el principio de no intervención, al configurarse como una especie de cortapisa a la excesiva intromisión del Estado en los espacios vivenciales propios de las personas y sus familias, debiéndose erigir, además, como una limitación a la hora de ejercer acciones en materia de derecho familiar.

Barrientos, por su parte, en su más que destacable obra de derecho de las personas, bajo el epígrafe "Protección del ejercicio de la autonomía privada en el momento de la crisis familiar", parece, a priori, tener la intención de conducirnos de algún modo al principio de mínima intervención. Ahora bien, el enfoque final que atribuye a su reflexión discurre sobre otros

la tendencia legislativa se ha encaminado a regular sus componentes de manera separada y a tratar a los miembros de la familia como seres autónomos e independientes.

${ }^{30}$ Corral Talciani, Hernán, Vida familiar y derecho a la privacidad, en Revista Chilena de Derecho, 26 (1999) 1, pp. 63-86.

${ }^{31}$ Ibíd., p. 79.

${ }^{32}$ Con todo, ibíd.., p. 84, el autor advierte "Sin perjuicio de lo anterior, pensamos que aquellas relaciones instauradas al margen del matrimonio, pero que presentan una estructura análoga a la familia matrimonial, sea biparental o monoparental, pueden también gozar, de un modo analógico y no propio' de un derecho a la intimidad familiar, pero sólo entendido como contenido del derecho individual al respeto de la vida privada en el plano de las relaciones familiares. No cabe, pensamos, predicar de los grupos familiares de hecho un derecho a la privacidad con titularidad colectiva, puesto que ello implicaría el reconocimiento institucional u orgánico de una entidad a la que le faltan los elementos estructurales para devenir en núcleo de intereses protegidos al margen de los derechos individuales, al menos a título de familia”. 
aspectos como lo son la desigualdad entre las partes en un proceso, en contexto de crisis familiar y la consecuente protección de la igual posición de negociación de los cónyuges.

No debemos, en esta sede, dejar de mencionar un fenómeno que se vislumbra con lo ya dicho, nos referimos a la constitucionalización que ha ido experimentando en los últimos años el derecho de familia ${ }^{33}$ derivado de otro fenómeno más amplio que se ha denominado, a su vez, la constitucionalización del derecho civil ${ }^{34}$, toda vez que la protección de las garantías fundamentales se ha ido imponiendo frente a los conceptos e instituciones que hasta hace poco tiempo servían para delimitar esta área del derecho, en tal sentido y a modo de ejemplo, es posible sostener que el contorno específico de la protección de la vida privada proyectada a la familia, denominado "intimidad familiar" ha debido ceder en múltiples ocasiones frente a la protección de otras garantías individuales de mayor jerarquía constitucional, como la protección de la vida o la integridad física o psíquica de los individuos ${ }^{35}$.

${ }^{33}$ Díaz de Valdés, José Manuel, Un marco constitucional para los tratamientos médicos de niños, niñas y adolescentes, en Revista Chilena de Derecho (2010) 2, p. 284, nos recuerda que la Constitución Estado reconoce a la familia como el núcleo fundamental de la sociedad (artículo 1 inciso $2^{\circ}$ ), así como que se atribuye al Estado el deber de darle protección y propender a su fortalecimiento (artículo 1 inciso $5^{\circ}$ ).

${ }^{34}$ Así Domínguez Águila, Ramón, Aspectos de la constitucionalización del derecho civil chileno, en Revista de Derecho y Jurisprudencia (1996) 3, p. 109, ha sostenido que tal fenómeno es de los más novedosos ocurridos en el derecho chileno: la constitucionalización del derecho civil, es decir, la acogida de normas y principios del derecho privado por la regla constitucional. La tendencia es convertir los derechos privados en garantías constitucionales para ponerlos a salvo de los atentados del resto del ordenamiento jurídico, pero también se observa la tendencia de convertir los más variados derechos, situaciones y aún hechos, en propiedad o dominio para así lograr la protección que el artículo $19 \mathrm{~N}^{\circ} 24$ consagra a este derecho el más eminente del ámbito civil patrimonial. Si antes un autor pudo decir "todo se hace derecho público", hoy podríamos decir, por el contrario: "todo se hace derecho de propiedad". Por su parte, ZúNiga, Yanira - Turner, Susan, cit. (n. 7), pp. 271-272, sustentan que la regulación constitucional de la familia se ha transformado en un verdadero colofón de un complejo proceso de transformaciones bidireccionales (desde lo social a lo jurídico y viceversa). A la clásica declaración política de que la familia es el núcleo fundamental de la sociedad, se ha debido sumar, paulatinamente, un cúmulo de disposiciones sustentivas que, en sede constitucional, se ocupan de regular el rol de la familia, las relaciones que se dan entre sus miembros (usualmente configuradas en clave de derechos fundamentales) y las vinculaciones entre la familia, por un lado, y la sociedad civil y el Estado, por el otro.

${ }^{35}$ Así se explica en fallo pronunciado por la Corte de Apelaciones de Talca, rol 133-2012, redactado por el Dr. Pinochet Olave, "6. Que debe considerarse al hablar de responsabilidad civil en el seno de la familia y, más aún, en el más restringido del ám- 
No obstante lo apuntado, y a diferencia de lo que acaece en buen número de constituciones de la región americana ${ }^{36}$, así como en la propia Constitución española de 1978, la Constitución de Chile, a pesar de atribuir a la familia, en su artículo 1 inciso $2^{\circ}$, el rol de "núcleo fundamental de la sociedad", en general carece de un estatuto sistemático sobre la referida institución que pueda orientar la regulación que de ella realiza el legislador, a efectos de atribuir derechos y obligaciones a sus miembros, ni las consecuencias jurídicas que derivan de la especial posición del Estado como garante de aquella ${ }^{37}$.

bito matrimonial, que supone referirse a un tema no por todos aceptado en derecho. Por una parte es posible encontrar aquellos que piensan que el derecho de la responsabilidad civil es del todo ajeno al derecho de familia, en la medida que la relación intima entre los miembros de la familia contrariaba la posibilidad de calificar a sus integrantes como dañadores o dañados. Por tal razón, de acuerdo a la posición doctrinal expuesta, resulta muy dudoso el papel que pueden jugar los remedios indemnizatorios propios del derecho de la responsabilidad civil respecto de los daños que se producian en la vida familiar o en las relaciones de convivencia. A estas dudas contribuye, según explica DAVID VARGAS ARAVENA (Profesor de derecho Civil de la Universidad Católica de Concepción), en primer lugar, la naturaleza misma de estas relaciones, que suelen generar vinculos de solidaridad $y$ desinterés contrarios a la formulación de reclamaciones jurídicas entre las partes afectadas. [...]. En definitiva, el derecho, como sistema de regulación de conductas, ha vuelto su mirada a la protección de los derechos individuales, y ha asumido que las instituciones (el matrimonio e incluso la familia) tienen como fundamento esencial el libre desarrollo de la personalidad humana y la integridad de sus miembros. Así, autores tales como Roca I Trías ("Familia y cambio social", De la casa a la persona, Civitas, 1ª edición, 1999, pp. 73 y ss.); Díez-Picazo y Gullón, (“Sistema de derecho civil”, Introducción, derecho de la persona, autonomía privada, persona jurídica; vol. I, 7a edición, Tecnos, 1990 , pp. 351 y ss.) están contestes en señalar que la familia es un instrumento al servicio del individuo, cuy a finalidad esencial es facilitar a sus miembros el ejercicio de los derechos fundamentales, asegurando a sus integrantes el armónico desarrollo de la personalidad y la garantía de los derechos y deberes de que es titular (David Vargas Aravena, La responsabilidad civil en el matrimonio: problemática en el ordenamiento español y su eventual aplicación al sistema chileno, en Gaceta Jurídica 312, 01/01/2006, 1). $7^{\circ}$ : Que aun cuando es difícil encontrar antecedentes en la jurisprudencia nacional, en algún caso, al confirmar la sentencia apelada, rechazando la indemnización solicitada, se ha sostenido que por el matrimonio se crea un ambiente de inmunidad para que los cónyuges se puedan reciprocamente dañar, con exclusión a toda norma de responsabilidad civil, amparados en un principio de especialidad del derecho de familia que permite aplicar sólo las sanciones o efectos expresamente previstos por el legislador, como por el carácter ético de las obligaciones y derechos que nacen de las relaciones de familia".

${ }^{36}$ Véanse, a título de ejemplo, las Constituciones de Argentina (1994), Bolivia (2009), Brasil (1988), Colombia (1991), Ecuador (2008), El Salvador (1983), Guatemala (1993), Paraguay (1992), Perú (1993), República Dominicana (2010) y Venezuela (2009).

${ }^{37}$ Añaden ZúNIgG, Yanira - Turner, Susan, cit. (n. 7), p. 277, que la hipertrofia 
Con todo, pensamos que la constitucionalización afecta más seriamente al derecho de familia que al derecho civil patrimonial, toda vez que según lo apuntado, estimamos que en la primera de las mencionadas áreas, la protección de las garantías fundamentales se ha ido imponiendo frente a los conceptos e instituciones que hasta no hace mucho tiempo servían para delimitarla, en tanto que en sede patrimonial la tendencia es convertir los derechos privados en garantías constitucionales, siendo el principal el derecho de propiedad, cuestión que no afecta la esencia del derecho civil patrimonial sino, por el contrario, la reafirma por ser este derecho uno de los pilares fundamentales sobre los cuales se construye el civil patrimonial, sin dejar de advertir, según decíamos, que también se observa la tendencia de convertir los más variados derechos y situaciones en propiedad para así lograr la protección que el artículo $19 \mathrm{~N}^{\circ} 24 \mathrm{CPol}$. establece a este derecho, el más eminente del ámbito civil patrimonial. Si antes un autor pudo decir "todo se hace derecho público", hoy podríamos decir, por el contrario: "todo se hace derecho de propiedad"38.

Como puede constatarse, no podemos referirnos al concepto de intimidad familiar sin relacionarnos directamente con el derecho constitucional a la vida privada y su protección, porque si algún contenido propio tenía el concepto de "vida familiar" hoy, de acuerdo con lo enunciado, lo ha perdido. Sin ser nuestra intención profundizar en temas hoy entregados al derecho constitucional, forzoso es concluir que, salvo algunas referencias perimetrales interesantes relacionadas con la protección de la intimidad familiar como proyección de la garantía a la vida privada, no hemos encontrado en el derecho de familia chileno referencias explícitas al mencionado principio de mínima intervención en asuntos de familia, ni menos análisis alguno acerca de su proyección y rol que debiera o no cumplir dentro de nuestro sistema normativo.

La diferencia de visión no nos parece relevante a menos que se esté indicando una forma distinta de método para comprender y aplicar esas normas. Es claro que el derecho civil no puede pretender mantener el método lógico-exegético a la hora de tratar esas normas, como si fueran preceptos del Código. Será, en definitiva, necesaria la interpretación teleológica o según principios que es la que conviene al texto constitucional.

Una aproximación sobre la base o desde la perspectiva de la no intervención en derecho de familia chileno, comparativamente hablando, debería provocar un doble efecto, tanto en abogados, partes y jueces. Por un lado,

abstencionista del constituyente original sumando a una regulación fragmentaria de la familia a nivel legal, han provocado una protección insuficiente y dispar de esta institución en el ordenamiento chileno.

${ }^{38}$ Domínguez Águila, Ramón, cit. (n. 34), p. 112. 
en abogados y partes, el principio de no intervención obliga a plantearse una serie de cosas antes de recurrir a la decisión judicial, por ejemplo, si recurrir al tribunal es la mejor opción para el asunto y si la decisión del juez será la mejor solución al problema. Mucho tiempo y dinero pueden ser ahorrados pensando en la cooperación y entendimiento parental. Por otro lado, en el caso de los jueces, sólo deben actuar, si interviniendo se obtiene un mejor resultado para el niño que no haciendo nada. Por lo tanto, de acuerdo con la perspectiva de la no intervención, el juez debe siempre dar razones explícitas ${ }^{39}$ justificando su decisión de intervención judicial en asuntos familiares, cualquiera que estos $\operatorname{sean}^{40}$.

\section{EL MODELO CONSTITUCIONAL DE PROTECCIÓN A LA FAMILIA Y A LA} INFANCIA EN EL SISTEMA NORMATIVO ESPAÑOL

\section{Aspectos generales.}

En el ordenamiento jurídico español, la familia encuentra su marco general de protección jurídica en el artículo 39 CPol.Esp., precepto éste que principia el capítulo $3^{\circ}$ del título $1^{\circ}$, donde se contienen los "principios rectores de la política social y económica", los cuales, como expresa el artículo 53,3 CPol.Esp., "informarán la legislación positiva, la práctica judicialy la actuación de los poderes públicos"41. Se trata, pues, de principios informadores, tal y como expresa el texto constitucional, y no de normas de aplicación directa. A ello se refiere el artículo 53,3 in fine del mismo texto constitucional cuando menciona que "sólo podrán ser alegados ante

${ }^{39}$ Debiera el juez, por ejemplo, explicar al menos por qué estima que actuando, su intervención producirá un beneficio o un beneficio mayor al niño, niña o adolescente comparado con la posibilidad de no hacer nada y, cómo en su actuar, se evidencian los elementos de razonabilidad y proporcionalidad en su actuación.

${ }^{40}$ Dawson, Peter - Stevens, Robert, Family Proceedings Court: A Handbook on the Children Act 1989 and The Rules for Practitioners \& Others (Chichester, Barry Rose Law Publishers, 1991), pp. 130 y 170.

${ }^{41}$ De acuerdo con Calvo Caravaca, Alfonso Luis - Carrascosa González, Javier, Derecho de familia internacional (Madrid, Colex, 2003), pp. 71-74, todos los modelos de familia que conviven en España son dignos de protección constitucional y legal, pues la Constitución española no acoge un concepto único y restrictivo de familia que deba ser objeto de atención. Es más, la familia a proteger jurídicamente no es sólo la "familia matrimonial" -sentencia del Tribunal Supremo 222/1992-, como lo fue en el pasado. Los casos en los que un "modelo de familia" no recibe protección jurídica deben ser delimitados con sumo cuidado, para no vulnerar el mandato constitucional de protección a la familia. Para BARUDY, Jorge, El dolor invisible de la infancia. Una lectura ecosistémica del maltrato infantil (Barcelona, Paidós, 1998), p. 41, la familia es un sistema complejo, a la vez viviente y humano, en interacción permanente con su medio ambiente. 


\section{la jurisdicción ordinaria de acuerdo con lo que dispongan las leyes que los desarrollen" ${ }^{42}$.}

Ese modelo o sistema de protección a la familia y salvaguarda de las personas menores de edad, acogido por el texto constitucional español en su artículo 39 ha sido calificado por la doctrina como mixto, o parcialmente público, basado en la estrecha correlación existente entre los ámbitos privado y público ${ }^{43}$; queriéndose con ello hacer énfasis en que las finalidades marcadas por el precepto en cuestión se cumplen tanto por el Estado ${ }^{44}$ (sistemas de seguridad social, servicios sociales, organismos públicos de protección a la infancia y la adolescencia), como por los particulares ${ }^{45}$ (alimentos entre parientes, obligaciones propias derivadas de la filiación, pensiones en caso de separación o divorcio).

${ }^{42}$ Chacón Villar, Pablo, Comentarios al artículo 39 de la Constitución, en CaSAS BaAmonde, María Eulalia - Rodríguez Piñero y Bravo-Ferrer, Miguel (directores), Comentarios a la Constitución española. XXX aniversario (Toledo, Fundación Walters Kluwer, 2009), p. 1004.

${ }^{43}$ Para Roca I Trías, Encarna, El nou dret català sobre la família, en Revista Jurídica de Cataluña (1999) 1, p. 10, en el contexto constitucional, el artículo 39 de la Constitución española establece un sistema calificado como mixto. Ello significa que la protección económica, social e incluso jurídica de la familia no queda limitada a los poderes públicos, sino que implica a los propios interesados, primordialmente a través de las obligaciones derivadas de la potestad, la tutela y los alimentos entre parientes. En este mismo sentido, véase RoCA I Trías, Encarna, Familia, familias y derecho de la familia, en Anuario de Derecho Civil (1990) 4, p. 1056. También, RocA I TRías, Encarna, Familia y cambio social (De la casa a la persona) (Madrid, Civitas, 1999), pp. 33, 66-68 y 222, defiende que el derecho español no se basa en una contraposición sector público y sector privado, sino en una cooperación entre ambos sectores, ya que las finalidades esenciales se obtendrán por medio de la atribución a cada uno de ellos de unas funciones específicas, en lo que se ha denominado sistema mixto. Esta misma idea también aparece en FlaQUeR VILARDEBÒ, Lluís (coordinador), Informe sobre la situación de la familia en Cataluña. Un intento de diagnóstico (Barcelona, Departamento de Bienestar Social de la Generalitat de Catalunya, 2002), p. 186. Por último, también se adscribe a este discurso Rivero HeRNÁNDEZ, Francisco, Protección civil de los menores en España. Lineas fundamentales en OLIVEIRA, Guiherme (editor), Direito da infancia, da juventude e do envelhecimento (Centro de Direito da Família. Faculdade de Direito da Universidade de Coimbra, No 9, Coimbra, Coimbra Editora, 2005), pp. 15-17.

${ }^{44}$ Flaquer Vilardebò, Lluís, Las políticas de apoyo a las familias, en GómeZ-Granell, Carme- García Milá, Mercè - Ripol-Millet, Aleix - Panchón, Carme (coordinadores), Infancia y familias: realidades y tendencias (Barcelona, Ariel, 2004), pp. 63-79, apunta que por lo que al Estado se refiere, éste debe establecer el sistema que permita a los ciudadanos gozar de la plenitud de sus derechos fundamentales y de la implementación de los derechos sociales, es decir, debe facilitar los medios e instrumentos necesarios para que toda persona desarrolle de manera plena su personalidad.

${ }^{45}$ Correspondería a los particulares prestar determinados servicios asistenciales, 
El citado mandato constitucional se manifiesta del siguiente tenor literal: "1. Los poderes públicos aseguran la protección social, económica y juridica de la familia.l 2. Los poderes públicos aseguran, asimismo, la protección integral de los hijos, iguales éstos ante la ley con independencia de su filiación, y de las madres, cualquiera que sea su estado civil.l 3. Los padres deben prestar asistencia de todo orden a los hijos habidos dentro o fuera del matrimonio, durante su minoría de edad y en los demás casos en que legalmente proceda.I 4. Los niños gozarán de la protección prevista en los acuerdos internacionales que velan por sus derechos".

Tal y como ha subrayado parte de la doctrina española, la distribución interna de este precepto cubre diversos aspectos de la protección familiar: la familia en general (núm. 1), los hijos y las madres (núm. 2), los deberes asistenciales derivados de la paternidad (núm. 3) y la protección de la infancia y la adolescencia conforme a los acuerdos internacionales (núm.4) ${ }^{46}$.

Una vez identificado el sistema de protección a la familia y salvaguarda de las personas menores de edad articulado en el texto constitucional español, procedemos acto seguido a un estudio pormenorizado de los principales aspectos que identifican el redactado del artículo 39 CPol.Esp..

\section{Análisis del artículo 39 de la "Constitución” española.}

Esta disposición, en sus cuatro apartados, diseña un programa constitucional, que trata de asegurar que toda persona menor de edad se desarrolle de manera plena y adecuada, interviniendo en el mismo dos tipos de fuerzas centrípetas: la privada, a través de las obligaciones que la Constitución impone a la familia; y la pública, mediante el desarrollo de la protección integral que se garantiza a los hijos y a aquéllos que deben contribuir a alcanzarla de una manera efectiva ${ }^{47}$.

que se proporcionan en el ámbito del grupo familiar y que deben tener también como finalidad última el garantizar a los miembros del grupo el disfrute efectivo de los derechos fundamentales, de acuerdo con el principio de solidaridad familiar. En este ámbito se colocan las relaciones paterno-filiales, los alimentos entre parientes y las pensiones y alimentos en los casos de separación y divorcio, entre otros.

${ }^{46}$ Espín Cánovas, Diego, Artículo 39. Protección de la Familia, en Alzaga VILlAAMIL, Óscar (director), Comentarios a la Constitución española de 1978 (Madrid, Edersa, 1996), IV, p. 47. Corrobora esta opinión GÁlvez MonTes, F. Javier, Comentarios al artículo 39 de la Constitución española, en GARRIDO FALLA, Fernando (director), Comentarios a la Constitución (Madrid, Civitas, 2001), p. 849, al configurar el artículo 39 de la Constitución española, como regulador de la protección a la familia, a los hijos y a la madre. La única referencia que en realidad excede del derecho de Familia es la contenida en el número 4, referida a la protección del niño.

${ }^{47}$ Según Roca i Trías, Encarna, El interés del menor como factor de progreso y unificación del derecho internacional privado (discurso de contestación al de ingreso de 
La referencia a la protección integral a la que alude el apartado segundo del artículo 39 CPol.Esp se incardinaría dentro de la calificada como protección social, económica y jurídica de la familia establecida en el punto primero del propio precepto ${ }^{48}$. El empleo de la expresión "asimismo" reforzaría esta afirmación, pues con ello el legislador ha querido plasmar idéntico haz tutelador dirigido a los hijos de familia ${ }^{49}$. Esa misma lectura interconectada de los distintos parágrafos que integran el artículo 39 CPol.Esp, ha impulsado a cierto número de autores a juzgar el redactado del segundo de sus incisos como de poco afortunado o no excesivamente feliz. En efecto, la protección que se proclama por parte de los poderes públicos respecto de los hijos (artículo 39,2 CPol.Esp.) sólo tiene sentido en tanto en cuanto que estos son menores de edad, lo que se convierte en una reiteración, desde el momento que a ellos se dedica en exclusiva el artículo 39,4 CPol.Esp..$^{50}$.

También ha suscitado ciertas controversias a nivel doctrinal el determinar si en el texto constitucional español se da o no cabida a manifestaciones concretas y específicas a la protección integral a la familia y a los hijos a que nos venimos refiriendo. Algunos autores se han pronunciado en forma negativa ${ }^{51}$; mientras que otros, por el contrario, sí creen entrever ciertas demostraciones de estos tres planos o ámbitos de intervención estatal en la norma suprema: el derecho a la intimidad familiar y la intervención de los padres en la educación de sus hijos, desde la óptica social; el derecho al trabajo y a una remuneración suficiente, en el ámbito económico; y la

la académica de número Dra. Alegría Borras, en la Academia de Jurisprudencia y Legislación de Cataluña), en Revista Jurídica de Cataluña (1994) 4, p. 976, el desarrollo que menciona el artículo 39 de la Constitución española no es otro que el previsto en el artículo 10 del propio texto constitucional, tal y como también pone de manifiesto el artículo 27.2. de la Constitución española al regular el objeto del derecho fundamental a la educación, "el pleno desarrollo de la personalidad humana en el respeto a los principios democráticos de convivencia y a los derechos y libertades fundamentales".

${ }^{48}$ GonzÁlez LeÓn, Carmen, El abandono de menores en el Código Civil (Barcelona, Bosch, 1995), p. 20.

${ }^{49}$ Martínez-Calcerrada Gómez, Luis, El nuevo derecho de familia, I: Estudio de la Constitución española y de la Ley de 13 de mayo de 1981 (Madrid, 1981), p. 41, añade a lo apuntado que los intereses de los hijos deberán ser tenidos en cuenta de manera preferente.

${ }^{50}$ En este sentido se manifiesta Alzaga VillaAmil, Óscar, Comentario sistemático a la Constitución española de 1978 (Madrid, Ediciones del Foro, 1978), p. 311.

${ }^{51}$ Escudero LuCAS, José Luis, La tuición del menor abandonado (artículo 172 del Código civil) (Murcia, Servicio de Publicaciones de la Universidad de Murcia, 1995), p. 19, sostiene que la Constitución no enumera el contenido de la protección familiar, sino que de modo general alude al ámbito social, económico y jurídico de esta protección, y no establece referencias concretas a la protección propiamente dicha. 
limitación, en aras al cuidado de la infancia, de las libertades reconocidas en el artículo 20 CPol.Esp. y el derecho a no declarar por razón de parentesco, desde la perspectiva jurídica.

Es importante también traer a colación que, a la hora de proteger a los hijos poco o nada importa el concepto de familia que encierre el precepto en cuestión, pues todos ellos son iguales ante la ley con independencia de su filiación, matrimonial o no matrimonial ${ }^{52}$. Además, al asumir la tutela de la familia rango constitucional y, dado el lugar prioritario que ocupa ésta en la jerarquía de las fuentes, hay autores que consideran que podría incluso hablarse de un derecho constitucional de la familia ${ }^{53}$.

Para encontrar los antecedentes del actual redactado del artículo 39 CPol.Esp., tenemos que remontarnos a la composición de la Constitución republicana de $1931^{54}$. Fue en este documento donde por primera vez en la historia constitucional española se contempló de manera expresa la protección pública de la familia y la infancia. El artículo 43 de la Constitución de 1931, precedente inmediato del actual artículo 39, era del siguiente tenor: "La familia está bajo la salvaguarda especial del Estado. El matrimonio se funda en la igualdad de derechos para ambos sexos, y podrá disolverse por mutuo disenso o a petición de cualquiera de los cónyuges, con alegación en este caso de justa causa. Los padres están obligados a alimentar, asistir, educar e instruir a sus hijos. El Estado velará por el cumplimiento de estos deberes y se obliga subsidiariamente a su ejecución. Los padres tienen para con los hijos

${ }^{52}$ Alonso Crespo, Evelia, Adopción nacional e internacional. Panorámica procesal y sustantiva, incluida la intervención de los padres biológicos. Formularios. Anexos (Las Rozas, Madrid, La Ley Actualidad, 2004), p. 13.

${ }^{53}$ Caparrós Civera, Neus - Jiménez-Aybar, Iván, El acogimiento familiar. Aspectos jurídicos y sociales (Madrid, Rialp, 2001), p. 45. Por su parte, Doral GarCÍA, José Antonio, Principios de derecho de familia (Granada, Facultad de Derecho de la Universidad de Granada, 1980), pp. 6-7, acoge esta misma expresión, si bien advierte dicho autor que la locución derecho constitucional de la familia no ha de llevarse, con todo, más allá de sus propios límites, por la siguientes razones: i) En el ámbito de dicha tutela no se incluye la protección ética de la familia; ii) Todo el derecho de familia sería derecho constitucional, dado el carácter sistemático del derecho y la trabazón que las normas, cualesquiera que sea su rango, tienen entre sí.

${ }^{54}$ Caparrós Civera, Neus - Jiménez-Aybar, cit. (n. 53), p. 45, creen ver en el artículo 22 del Fuero de los Españoles de 1945 un antecedente al artículo 39 de la Constitución española. Este precepto establecía que "el Estado reconoce y ampara la familia como institución natural y fundamento de la sociedad, con derechos y deberes anteriores y superiores a toda Ley humana positiva". Por su parte, GÁlvez MonTES, F. Javier, cit. (n. 46), p. 848, también invoca como precedente al artículo 39 de la Constitución española, la Declaración III, 1 del Fuero del Trabajo de 1938, que se pronuncia del siguiente tenor: "La retribución del trabajo será, como minimo suficiente para proporcionar al trabajador y su familia una vida moral y digna". 
habidos fuera del matrimonio los mismos deberes que respecto de los nacidos en él. Las Leyes civiles regularán la investigación de la paternidad. No podrá consignarse declaración alguna sobre la legitimidad o ilegitimidad de los nacimientos ni sobre el estado civil de los padres, en las actas de inscripción, ni en filiación alguna. El Estado prestará asistencia a los enfermos y ancianos y protección a la maternidad y a la infancia haciendo suya la Declaración de Ginebra o tabla de los derechos del niño"55.

Tal y como puede comprobarse el precepto republicano opta, en primer lugar, por declarar de forma genérica que la "familia está bajo la salvaguarda especial del Estado", sin entrar a concretar qué se entiende por esa defensa o amparo singular que se irroga a tal institución. El texto del artículo 39 CPol.Esp., en cambio, es más preciso al delimitar y encuadrar la actividad de los poderes públicos en atención a la familia a las dimensiones: social, económica y jurídica ${ }^{56}$. Por otra parte, mientras que el artículo 43 de la Constitución de 1931 especifica el contenido del deber de asistencia de los padres con respecto a sus hijos, al prescribir que "los padres están obligados a alimentar, asistir, educar e instruir a sus hijos", no acaece lo mismo en la vigente Constitución, en que se prefiere la expresión más global de "prestar asistencia de todo orden". Correspondiendo la tarea de definir dicha prestación o mandato legal no al nivel constitucional sino al legislador ordinario ${ }^{57}$. Así, estos deberes paternos para con sus hijos aparecen detallados en el artículo 154 CCEsp.: "velar por ellos, tenerlos en su compañia, alimentarlos, educarlos y procurarles una formación integral; asi como representarlos y administrar sus bienes". En idéntico sentido se pronuncia el artículo 236,17 $\mathrm{N}^{\circ} 1^{\circ}$ del Código Civil de Cataluña.

Finalmente, ambos textos -aunque con mayor claridad la Constitución de 1978- concluyen con sendas cláusulas de cierre del sistema de protección de menores. El artículo 39 al hacer una remisión expresa a los acuerdos internacionales que velen por los derechos de los niños, niñas y adolescentes; y el artículo 43, por su parte, al hacer lo propio con la "Declaración de Ginebra" o tabla de los derechos de la niñez.

Esta alusión contenida en el punto 4 del artículo 39 CPol.Esp. a la "protección de los niños prevista en los acuerdos internacionales que velan

${ }^{55}$ Para un análisis detallado del artículo 43 de la Constitución de 1931, véase: Fosar Benlloch, Enrique, Estudios de derecho de familia. Tomo I. La Constitución de 1978 y el derecho de familia (Barcelona, Bosch, 1981), pp. 65-82.

${ }^{56}$ Martínez-Calcerrada, Luis, cit. (n. 49), pp. 37-40, desarrolla lo que en su opinión queda comprendido dentro de las tres esferas de protección de la familia: social, económica y jurídica. La misma operación realiza Espín CÁNOVAS, Diego, cit. (n. 46), pp. 51-52.

${ }^{57}$ Escudero LuCAS, José Luis, cit. (n. 51), p. 20. 
por sus derechos", consecuencia de la controversia provocada por el olvido que al respecto sufrió el Borrador de la Ponencia ${ }^{58}$, ha sido objeto de múltiples interpretaciones ${ }^{59}$. Mientras que algunos autores la perciben como una reiteración de las previsiones ya estipuladas en los artículos 96 y 10,2 del propio texto constitucional ${ }^{60}$ o incluso como una simple norma en blanco ${ }^{61}$; otros, en cambio, marcan una línea divisoria entre los acuerdos internacionales ratificados por España y los que no lo hayan sido. Los primeros, una vez sancionados y publicados en el Boletín Oficial del Estado pasan a formar parte del ordenamiento jurídico interno, como reconoce la propia Constitución en su artículo 96, y su modificación está sujeta tanto a las reglas prefijadas en el propio texto convencional como a las generales del derecho internacional público. Mayor dificultad ofrecen los tratados internacionales que no hayan sido ratificados por España, ya que no puede entenderse que formen parte de la normativa española. En este último supuesto, el artículo 39,4 de la Constitución de 1978 lejos de ser considerado como un precepto baladí o vacío de contenido, cumple

${ }^{58}$ Este precepto constitucional, que no figuraba en el Anteproyecto (Boletín Ofcial del Congreso, de 5 enero de 1978), fue postulado en las enmiendas registradas con los números 5 (de la señora Fernández-España), 22 (del señor Jarabo Payá), 48 (del señor Gómez de las Roces), 183 (del Grupo Parlamentario Minoría Catalana), 481 (del Grupo Parlamentario Mixto) y 162 (del Grupo Parlamentario Vasco). En la motivación de la primera de estas enmiendas se argumentaba que resulta incoherente la omisión de tan fundamental cuestión en el texto constitucional, teniendo en cuenta que hace cuarenta y seis años que el artículo 46 de la Constitución de 1931 recogió la Declaración de Ginebra o Tabla de los derechos del Niño, y diecinueve años desde que nuestro país votó afirmativamente, el 20 de noviembre de 1959, en la Asamblea General de las Naciones Unidas, la Declaración de los derechos del Niño. MarTínEZCalcerrada, Luis, cit. (n. 49), p. 63, nos recuerda que el punto cuarto del artículo $39 \mathrm{CE}$, es consecuencia de una reiterada campaña parlamentaria y FoSAR BENLLOCH, Enrique, cit. (n. 55), pp. 247-248, en la misma línea, también alude al olvido de los derechos del niño en la redacción del borrador de la ponencia constitucional, y a la campaña que entidades como Unicef/España hicieron para subsanar tal descuido.

${ }^{59} \mathrm{Al}$ respecto de este apartado cuarto, Alzaga VillaAmil, Óscar, cit. (n. 50), pp. 153 y 313, se pregunta si no hubiera sido camino más rápido y conducente a la adopción de fórmulas elaboradas y estilísticamente más felices, el constitucionalizar las tablas de derechos y libertades de la Declaración Universal de las Naciones Unidas, de la Carta Europea, e incluso de la Declaración de los derechos del niño aprobada por las Naciones Unidas, el 29 de noviembre de 1959.

${ }^{60}$ GonZÁlez LeÓn, Carmen, cit. (n. 48), pp. 20-21, considera el apartado cuarto del artículo 39 de la Constitución española como redundante si se atiende a los artículos 96 y 10.2 de la misma.

${ }^{61}$ Martínez-Calcerrada Gómez, Luis, cit. (n. 49), p. 63, reputa que el precepto es como una norma en blanco que, obviamente, precisará una acomodación legislativa a los diferentes acuerdos internacionales, en vía de desarrollo. 
una función normativa importante como fuente de inspiración programática del futuro legislador y como criterio exegético de otras disposiciones vigentes ya en el derecho español, que permitan un aproximación por vía deductiva a los pactos y acuerdos internacionales ${ }^{62}$.

\section{BIBLIOGRAFÍA}

Acuña San Martín, Marcela, Efectos jurídicos del divorcio (Santiago de Chile, Abeledo Perrot, 2011).

Alonso Crespo, Evelia, Adopción nacional e internacional. Panorámica procesal y sustantiva, incluida la intervención de los padres biológicos. Formularios. Anexos (Las Rozas [Madrid], La Ley Actualidad, 2004).

Alzaga Villaamil, Óscar, Comentario sistemático a la Constitución española de 1978 (Madrid, Ediciones del Foro, 1978).

Arancibia Obrador, María José - Cornejo Aguilera, Pablo, El derecho de familia en Chile. Evolución y nuevos desafios, en Ius et Praxis (2014) 1.

Ávila, Humberto, Teoría de los principios (traducción de Laura Criado, Madrid, Marcial Pons, 2011).

Barcia Lehmann, Rodrigo, Fundamentos del derecho de familia y de la infancia (Santiago, Thomson Reuters, 2011).

BARUDY, Jorge, El dolor invisible de la infancia. Una lectura ecosistémica del maltrato infantil (Barcelona, Paidós, 1998).

Borras Rodríguez, Alegría, El interés del menor como factor de progreso y unificación del derecho internacional privado (discurso de ingreso en la Academia de Jurisprudencia y Legislación de Cataluña), en Revista Jurídica de Cataluña, 93 (1994) 4.

BRUllet, Cristina - TORRABADELla, Laura, La infancia en las dinámicas de transformación familiar, en Gómez- Granell, Carme - García Milá, Mercè - Ripol-Millet, Aleix - PANCHÓN, Carme (coordinadores), Infancia y familias: realidades y tendencias (Barcelona, Ariel, 2004).

Brullet, Cristina - RocA, Clara, Relaciones familiares y autoridad, en Infancia, familias y cambio social en Cataluña, 1 (Barcelona, Instituto de Infancia y Mundo Urbano. Observatorio de la Infancia y las Familias, 2005).

BURT, Robert, Desarrollo constitucional de derechos de, sobre y para menores, en BELOFF, Mary (coordinadora), Derecho, infancia y familia (Barcelona, Gedisa, 2000).

Calvo Caravaca, Alfonso Luis - Carrascosa González, Javier, Derecho de familia internacional (Madrid, Colex, 2003).

${ }^{62}$ Escudero Lucas, José Luis, cit. (n. 51), p. 21; y Espín Cánovas, Diego, cit. (n. 46), p. 61. Un posicionamiento similar mantiene Fosar BENLlOCH, Enrique, cit. (n. 55), pp. 248-249, quien tras criticar a Alzaga por sostener que el apartado cuarto del artículo $39 \mathrm{CE}$ requiere de un desarrollo legislativo para incorporar a nuestro Ordenamiento jurídico los derechos del niño, manifiesta que en la medida en que las Convenciones y Pactos hayan sido ratificados por España y en la medida en que establezcan verdaderos derechos y no simples declaraciones programáticas, es evidente que por obra de la recepción automática no precisan de desarrollo legal ninguno para ser incorporados a nuestro sistema normativo interno. 
Caparrós Civera, Neus - Jiménez-Aybar, Iván, El acogimiento familiar. Aspectos jurídicos y sociales (Madrid, Rialp, 2001).

Chacón Villar, Pablo, Comentarios al artículo 39 de la Constitución, en CaSas BaAmonde, María Eulalia - Rodríguez Piñero - Bravo-Ferrer, Miguel (directores), Comentarios a la Constitución española. XXX aniversario (Toledo, Fundación Walters Kluwer, 2009).

Cillero Bruñol, Miguel, El interés superior del niño en el marco de la Convención internacional de los derechos del niño, en Justicia y derechos del niño (UNICEF, 1999) 1.

Cillero Bruñol, Miguel, El interés superior del niño en el marco de la Convención Internacional de los Derechos del Niño, en Justicia y Derechos del Niño (UNICEF, 2007) 9.

Corral Talciani, Hernán, Vida familiar y derecho a la privacidad, en Revista Chilena de Derecho, 26 (1999) 1.

CORTE INTERAMERICANA DE DERECHOS HUMANOS: Opinión Consultiva OC-17/2002, de 28 de agosto, solicitada por la Comisión Interamericana de Derechos Humanos.

Dawson, Peter - Stevens, Robert, Family Proceedings Court: A Handbook on the Children Act 1989 and The Rules for Practitioners \& Others (Chichester, Barry Rose Law Publishers, 1991).

Del Picó Rubio, Jorge, Derecho matrimonial chileno (Santiago, Abeledo Perrot, 2010).

Del Picó Rubio, Jorge, Evolución y actualidad de la concepción de familia. Una apreciación de la incidencia positiva de las tendencias dominantes a partir de la reforma del derecho matrimonial chileno, en Ius et Praxis (2011) 1.

Díaz de VALdés, José Manuel, Un marco constitucional para los tratamientos médicos de niños, niñas y adolescentes, en Revista Chilena de Derecho (2010) 2.

Díez-Picazo y Ponce de León, Luis, La reforma del Código Civil en materia de patria potestad, en la reforma del derecho de familia, matrimonio, separación, divorcio, régimen económico matrimonial, fliación y patria potestad. Jornadas Hispalenses sobre la Reforma del derecho de familia (Sevilla, Imprenta Sevilla, 1983).

Díez-PiCAzo y PonCe de LeÓn, Luis, Notas sobre la reforma del Código Civil en materia de patria potestad, en Anuario de Derecho Civil, 35 (enero-marzo de 1982).

Domínguez Águila, Ramón, Aspectos de la constitucionalización del derecho civil chileno, en Revista de Derecho y Jurisprudencia (1996) 3.

Domínguez Hidalgo, Carmen, Los principios que informan el derecho de familia chileno: su formulación clásica y su revisión moderna, en Revista Chilena de Derecho (2005) 2.

Doral García, José Antonio, Principios de derecho de familia (Granada, Universidad de Granada, 1980).

Escudero LuCAS, José Luis, La tuición del menor abandonado (artículo 172 del Código civil) (Murcia, Servicio de Publicaciones de la Universidad de Murcia, 1995).

Espín Cánovas, Diego, Artículo 39. Protección de la Familia, en Alzaga Villaamil, Óscar (director), Comentarios a la Constitución española de 1978 (Madrid, Edersa, 1996), IV.

FERnÁNDEZ MASÍA, Enrique, Las entidades públicas y la protección de los menores extranjeros en España, en Actualidad Civil, 19 (mayo, 1998).

FlaQUer VILARDEbò, Lluís (coordinador), Informe sobre la situación de la familia en Cataluña. Un intento de diagnóstico (Barcelona, Departamento de Bienestar Social. Generalitat de Catalunya, 2002).

Flaquer Vilardebò, Lluís, Las políticas de apoyo a las familias, en Gómez-Granell, 
Carme - García Milá, Mercè - Ripol-Millet, Aleix - Panchón, Carme (coordinadores), Infancia y familias: realidades y tendencias (Barcelona, Ariel, 2004).

Fosar Benlloch, Enrique, Estudios de derecho de familia, I: La Constitución de 1978 y el derecho de familia (Barcelona, Bosch, 1981).

Gala Vallejo, César, La familia y su protección en España (Madrid, Ministerio de Trabajo y Asuntos Sociales, 2002).

Gálvez Montes, F. Javier, Comentarios al artículo 39 de la Constitución española, en Garrido Falla, Fernando (director), Comentarios a la Constitución (Madrid, Civitas, 2001).

Garcés Sanagustín, Ángel, Acción social. La protección de menores, en Embid Irujo, Antonio (director), Derecho público aragonés (Zaragoza, El Justicia de Aragón, 2005).

Gatica, Nora - Chaimovic, Claudia, La justicia no entra en la escuela. Análisis de los principales principios contenidos en la Convención sobre los derechos del Niño, en La Semana Jurídica (del 13 al 19 de mayo de 2002).

Glendon, Mary Ann, The Transformation of Family Law. State, Law, and Family in the United States and Western Europe (Chicago, The University of Chicago Press, 1989).

Gómez de la TORRe VARGas, Maricruz, El interés superior del niño, en Gaceta Jurídica, 328 (2000).

González León, Carmen, El abandono de menores en el Código Civil (Barcelona, Bosch, 1995).

Grosman, Cecilia - Martínez Alcorta, Irene, Familias ensambladas. Nuevas uniones después del divorcio. Ley y creencias. Problemas y soluciones legales (Buenos Aires, Editorial Universidad, 2000).

LÁzAro GonZÁlez, Los menores en el derecho español (Madrid, Tecnos, 2002).

Lepin Molina, Cristian, La autonomía de la voluntad y protección del cónyuge más débil en la determinación y formas de pago de la compensación económica, en Ius et Praxis (2012) 1.

Lepin Molina, Cristian, Los nuevos principios del derecho de familia, en Revista Chilena de Derecho Privado, 23 (2014).

Martínez-Calcerrada Gómez, Luis, El nuevo derecho de familia, I: Estudio de la Constitución española y de la ley de 13 de mayo de 1981 (Madrid, 1981).

Mason, Mary Ann, ¿Una voz para el niño?, en Revista de Derechos del Niño (UDPUNICEF) (2004) 2.

O’Donell, Daniel, La Convención sobre los derechos del niño: estructura y contenido (materiales de un curso dirigido a especialistas del área jurídica de la niñez organizado por el Instituto Interamericano de la Niñez (Instituto Interamericano de la Niñez, 2005).

Orrego Acuña, Juan Andrés, Temas de derecho de familia (Santiago de Chile, Metropolitana, 2007).

Ortuño Muñoz, Pascual, Los procesos en los juzgados de familia (Consejo General del Poder Judicial).

Palma del Teso, Ángeles de, La protección de los menores por las administraciones públicas, en Revista Jurídica de Cataluña (2004) 2.

Rivero Hernández, Francisco, Protección civil de los menores en España. Lineas fundamentales en Oliveira, Guiherme (director), Direito da infancia, da juventude e do envelhecimento. Centro de Direito da Familia. Faculdade de Direito da Universidade de Coimbra, 9 (Coimbra, Coimbra Editora, 2005). 
Roca I TRÍAS, Encarna, El interés del menor como factor de progreso y unificación del derecho internacional privado (discurso de contestación a la académica de número Dra. Alegría Borras, en su discurso de ingreso en la Academia de Jurisprudencia y Legislación de Cataluña, en Revista Jurídica de Cataluña (1994) 4.

Roca I TRÍAs, Encarna, El nou dret català sobre la família, en Revista Jurídica de Cataluña (1999) 1.

Roca I TRÍAs, Encarna, Familia y cambio social (De la casa a la persona) (Madrid, Cuadernos Civitas, 1999).

Roca I Trías, Encarna, Familia, familias y derecho de la familia, en Anuario de Derecho Civil (1990) 4.

Rochefort, Christiane, Los niños primero (Barcelona, Anagrama, 1982).

Rodríguez Pinto, María Sara, El cuidado personal de niños y adolescentes en la familia separada: criterios de resolución de conflictos de intereses entre padres e hijos en el nuevo derecho chileno de familia, en Revista Chilena de Derecho (2009) 3.

TAPia Rodríguez, Mauricio, Del derecho de familia hacia un derecho de las familias en GuZmán Brito, Alejandro (editor), Estudios de derecho civil. Jornadas Nacionales de derecho civil. Valparaiso (Santiago, Abeledo-Perrot, 2007), III.

Vargas Aravena, David, La responsabilidad civil en el matrimonio: problemática en el ordenamiento español y su eventual aplicación al sistema chileno, en Gaceta Jurídica, 312 (enero 2006).

Vlaardingerbroeck, P, Child Care and Protection Measures and Minor Foreigners: The Legal Position of Minors, en Lowe, N. - Douglas, G. (editores), Family Across Frontiers (London, 1996).

ZúNiga, Yanira - Turner, Susan, Sistematización comparativa de la regulación de la familia en las constituciones latinoamericanas, en Revista de Derecho de la Universidad Católica del Norte (2013) 2. 